\title{
POLUIÇÃO DO AR E SAÚDE NOS PRINCIPAIS CENTROS COMERCIAIS DA CIDADE DE NATAL/RN
}

\author{
Karina Messias da Silva Alves \\ Aluna do Curso de Especialização em Gestão Ambiental do IFRN. \\ E-mail:karinatrn@yahoo.com.br \\ Adriano Eduardo Lívio Alves \\ Aluno do Curso de Especialização em Gestão Ambiental do IFRN. \\ Email: drianlivio@yahoo.com.br \\ Fernando Moreira da Silva \\ Professor do Curso de Geografia da UFRN. Email: fmoreyra@ufrnet.br
}

\begin{abstract}
RESUMO
O fenômeno da poluição do ar potencializada, principalmente, pelo aumento da frota de veículos, que, associados a fatores meteorológicos (temperatura do ar, umidade, pressão), tem contribuído para com a concentração de poluentes e material particulado em suspensão na atmosfera. A cidade de Natal/RN, nos últimos dez anos (1998-2008), vem apresentando indícios da poluição do ar por entre algumas áreas da cidade. O estudo se reverte em uma linha de pesquisa de significativa relevância, pois são poucos os trabalhos acadêmicos encontrados na cidade que se enveredam por esse tema da poluição do ar e saúde daqueles que trabalham diariamente nas áreas comerciais. A pesquisa teve como recorte espacial os centros comerciais localizados nos bairros da Cidade Alta, Ribeira e do Alecrim. Os critérios considerados para a seleção da população amostral foram: 1-somente as pessoas que trabalhavam em ambientes abertos, 2- pessoas não fumantes, 3 trabalhadores que permanecessem no local de trabalho por um período diário considerável. Os procedimentos metodológicos utilizados foram: pesquisa bibliográfica e entrevista com 108 pessoas, além da utilização dos recursos da estatística gráfica para o tratamento dos dados. Os resultados obtidos revelam que a poluição nesses centros comerciais apresenta índices consideráveis manifestados nas pessoas através da aparição de sintomas ligados a problemas respiratórios.
\end{abstract}

Palavras - chave: Poluição do ar, Doenças respiratórias, Fluxo de veículos. 


\section{POLUIÇÃO DO AR E SAÚDE NOS PRINCIPAIS CENTROS COMERCIAIS DA CIDADE DE NATAL/RN}

\section{INTRODUÇÃO}

O intenso processo de urbanização e industrialização tem colocado em risco a qualidade de vida dos habitantes das áreas urbanas, risco este, relacionado com o ar que se respira nas cidades. O aumento da frota de veículos, associados a fatores meteorológicos como a temperatura do ar, pressão e umidade, têm contribuído para com a concentração de poluentes em suspensão na atmosfera, gerando um clima urbano poluído e propício a desencadear diversos tipos de doenças aos habitantes dos grandes centros urbanos.

No Brasil, seus principais centros urbanos como São Paulo e Rio de Janeiro, são acometidos pela poluição do ar de origem tanto industrial quanto veicular. Por esse fato que os primeiros registros no Brasil da manifestação de doenças relacionadas à poluição do ar ocorreram nessas cidades. A partir desses acontecimentos, verificados nos principais centros urbanos do Brasil, que o tema da poluição do ar despertou o interesse na comunidade acadêmica de várias cidades Brasileiras, através da realização de estudos para a investigação dos indícios da poluição do ar e dos seus efeitos na saúde humana.

Porém, na cidade de Natal/RN, os estudos relacionados com a poluição do ar começaram a ser desenvolvidos recentemente, por volta de um período aproximado de dez anos (19982008). O curto período de estudo sobre a poluição do ar recai sobre o fato de foi a partir do momento que a cidade começou a apresentar um crescimento significativo na sua frota de veículos, que o fenômeno da poluição do ar passou a se manifestar por entre alguns espaços na cidade, notadamente, nos centros comerciais, onde há uma grande circulação e concentração de veículos trafegando diariamente.

A justificativa para a escolha do tema centra-se no fato de que em algumas áreas na cidade, existem indícios da ocorrência da poluição do ar, constatados em estudos feitos por alguns pesquisadores acadêmicos, que ao analisarem a poluição do ar na cidade de Natal/RN, tendo como indicadores de poluição a água da chuva (MACÊDO, 2004, MELO, 2007, ALVES, 2009), obtiveram resultados que apontavam para a existência de uma provável contaminação do ar em algumas áreas na cidade. Dessa forma, o estudo se reverte em uma linha de pesquisa de grande importância, pois se trata de uma vertente nos estudos sobre a poluição do ar, considerando a visão da população exposta constantemente aos poluentes atmosféricos.

O objetivo geral da pesquisa foi investigar os efeitos da poluição do ar nas principais áreas comerciais da cidade de Natal/RN pela visão da população trabalhadora. Como objetivos de natureza específica, se destacam: analisar se as pessoas que trabalham nos centros comerciais de Natal/RN percebem a poluição do ar e quais os principais sintomas percebidos dessa poluição, e investigar quais os principais pontos da cidade onde ocorrem maiores casos de doenças ocasionadas pela poluição do ar. 


\section{ÁREA DE ESTUDO}

Tecendo um breve comentário sobre as principais características físicas de Natal, tem-se que, a cidade está localizada na região Nordeste do país, onde segundo Nunes (2000), o clima de Natal é classificado como As’ de acordo como sistema de Köppen, que é caracterizado como tropical chuvoso (quente e úmido), com verão seco e inverno bastante intenso.

Segundo informações do Laboratório de Climatológica da UFRN, a temperatura média anual é de $25,4{ }^{\circ} \mathrm{C}$ com uma temperatura máxima na média mensal de $30,3{ }^{\circ} \mathrm{C}$ e as temperaturas médias das mínimas de $24,1^{\circ} \mathrm{C}$, enquanto a média da amplitude térmica é de $6,2^{\circ} \mathrm{C}$, caracterizando uma maior uniformidade comparando a outras capitais. A insolação média anual é de 2.986 horas e a umidade relativa do ar com uma média anual de $77 \%$, sendo os meses mais úmidos de fevereiro a agosto e os menos úmidos de setembro a janeiro.

Segundo Medeiros (2001), a cidade de Natal caracteriza-se por apresentar um alto grau de heterogeneidade espacial e temporal do seu regime pluviométrico, ocasionando com isso anos com excesso de precipitação, contrastando com anos que apresentam elevado déficit pluviométrico. Quanto à precipitação média em Natal no período de 1997 a 2003 foi de $2.248 \mathrm{~mm}$. A estação chuvosa em Natal estende-se de fevereiro a agosto, quando os totais mensais, em média, excedem os $110 \mathrm{~mm}$, e de outubro a dezembro têm-se os meses mais secos, com o total de precipitação em média, abaixo de $40 \mathrm{~mm}$.

Em um quadro geral, os ventos apresentam uma notável constância, os Alísios de sudeste apresentando valores elevados com intensidade de $5 \mathrm{~m} / \mathrm{s}$, soprando durante 211 dias por ano. Ventos de leste são predominantes durante 102 dias por ano, já os ventos de sul sopram durante 37 dias, e apenas 15 dias têm-se ventos calmos.

No que se refere às características de sua população, a cidade de Natal apresenta um quadro populacional, com um número de 774.230 (setecentos e setenta e quatro mil e duzentos e trinta) habitantes, segundo a última contagem populacional realizado pelo Instituto Brasileiro de Geografia e Estatística - IBGE, no ano de 2007.

Sobre o recorte espacial, toma-se como base para análise as principais áreas comerciais da cidade, inseridas nos bairros da Ribeira, Cidade Alta e do Alecrim, todos, localizados na Região Leste da cidade de Natal.

Dos centros comerciais abarcados pela pesquisa, todos apresentam seu caráter comercial, possuindo estabelecimentos em diversos segmentos econômicos, diferenciando apenas, a intensidade e variedade das atividades comerciais, ou seja, os bairros da Cidade Alta e do Alecrim apresentam intensa atividade comercial, como também um fluxo considerado de trabalhadores (formais e informais), como o de pessoas atraídas pelos serviços oferecidos nessas duas áreas. No entanto, o Bairro da Ribeira, desenvolve sua função comercial, embora com um número reduzido de estabelecimentos comerciais.

Além do fluxo de pessoas, o fluxo de veículos é bem expressivo na Cidade Alta e no Alecrim, sendo moderado na Ribeira. Por entre essas três áreas comerciais, existe um considerado movimento na circulação de veículos automotores, como os transportes de passageiros (ônibus e alternativos), carros de passeio, caminhões e demais veículos. Outra 
característica quanto à circulação de veículos por entre esses três bairros é que quase todos os ônibus e alternativos que circulam pelas quatro regiões administrativas da cidade, passam pelos bairros pesquisados. A Figura 1, a seguir, trás a localização da área em estudo:

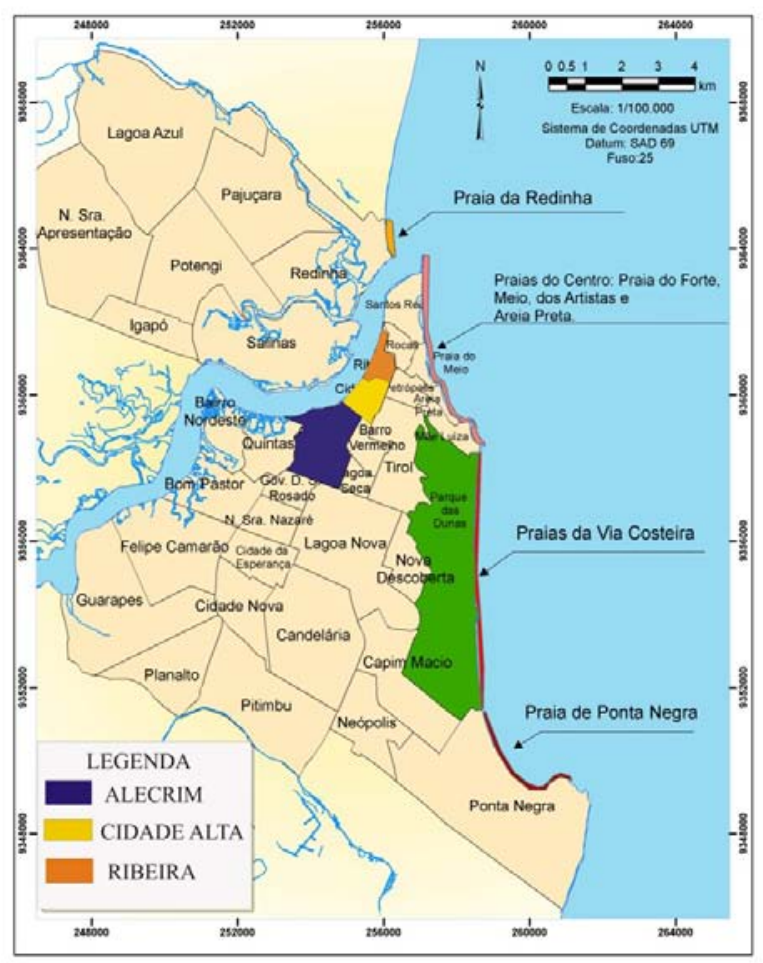

Figura 1- Localização da área em estudo

\section{METODOLOGIA}

Dentre os procedimentos metodológicos utilizados para a realização do estudo, estão: pesquisa de campo, revisão bibliográfica, com a utilização de livros, artigos científicos e trabalhos acadêmicos sobre a temática da poluição do ar, em âmbito mundial, nacional e, em especifico da cidade de Natal. Outras fontes secundárias também enriqueceram o referencial teórico do estudo, como: material de cunho jornalístico, extraído de um dos principais jornais de grande circulação no estado do Rio Grande do Norte, A Tribuna do Norte, além de informações estatísticas e históricas sobre a cidade de Natal, contidas em publicações feitas pela Prefeitura de Natal, através da Secretaria Municipal de Meio Ambiente e Urbanismo - SEMURB.

\section{Coleta de Dados}

O recorte temporal estabelecido para o inicio do processo investigativo do estudo, bem como para a obtenção de dados referente ao histórico da poluição do ar em Natal/RN, através do trabalho de gabinete, teve seu ponto de partida estipulado a partir do ano 1998 até o ano de 2008. Por conseguinte, a escolha por esse recorte temporal é devido ao fato de se tratar de um período onde começaram a surgir os primeiros trabalhos acadêmicos explorando o tema da poluição do ar na cidade de Natal. 
Com relação à coleta de dados de campo, optou-se pela utilização da técnica de questionários, onde foi aplicada a quantia de cento e oito (108) questionários junto às pessoas que trabalhavam por entre o recorte espacial do estudo, perfazendo os bairros da Cidade Alta, Ribeira e do Alecrim. A aplicação dos questionários foi realizada no período compreendido entre os dias 16 e 19 de junho de 2009.

Os questionários foram aplicados de acordo com critérios, obedecendo alguns cuidados, afim de não prejudicar os resultados investigados. Os critérios seguidos foram:

1- Somente as pessoas que não manifestavam o hábito de fumar. Tal critério de seleção foi empregado, pois o ato de fumar alteraria o resultado na análise da pesquisa, ao correlacionar a aparição de doenças respiratórias na população entrevistada com a poluição do ar em seu local de trabalho;

2- Fez parte do universo da pesquisa, somente as pessoas que trabalhavam em ambientes abertos, ou seja, vendedores que estavam diretamente em contato com a fumaça dos carros, como os que trabalhavam em estabelecimentos que não fossem fechados ou que em seu interior não possuíssem aparelhos com ar condicionado, além dos vendedores instalados nas calçadas das ruas e avenidas de tráfego intenso.

3- Para saber o tempo que aquelas pessoas estavam expostas diretamente ao material poluente expelido pelos carros (carros de passeio, caminhão, ônibus, alternativos, motocicletas), havia o quesito no questionário que perguntava quantas horas por dia cada pessoa entrevistada trabalhava na área. Esta pergunta teve o intuito de considerar somente trabalhadores que permanecessem no local de trabalho, por um período diário considerável para que os sintomas da poluição do ar pudessem se manifestar.

\section{Fundamentação Gráfica}

O estudo utilizou, para a interpretação dos dados da população amostral, os recursos da Estatística Gráfica, uma vez que, ela é empregada, a partir do momento em que as informações da amostra já foram coletadas e observadas. Feito isso, inicia-se o passo seguinte a ser seguido, que consiste em "introduzir técnicas que permitam organizar, resumir e apresentar estas informações, de tal forma que possamos interpretá-los à luz dos objetivos da pesquisa” (BARBETTA, 2002.p.69).

Essa parte da estatística possibilita a descrição e interpretação dos dados das variáveis utilizadas no estudo. As variáveis contidas nos questionários foram: sexo, idade, grau de instrução, bairro onde reside e trabalha, além das perguntas inseridas na problemática do estudo. Para a análise desses dados qualitativos e das perguntas diretamente ligadas à temática em questão, primeiramente os resultados foram dispostos em gráficos, que no segundo momento, permitiu a interpretação dos resultados.

Por conseguinte, o estudo utilizou-se dessa técnica da interpretação gráfica para expor seus resultados, com apresentação das informações categorizadas expressas em gráficos na forma de colunas: onde cada categoria é representada por uma barra de comprimento proporcional à sua freqüência (BARBETTA, 2002). Por fim, os gráficos foram elaborados através do programa computacional Microsoft Excel 2007. 


\section{POLUIÇÃO ATMOSFÉRICA}

Problemas ambientais, como a poluição do ar, bastante comum nas grandes áreas urbanas, são preocupações que envolvem a Ciência Geográfica, pois se trata de uma das conseqüências da produção do espaço geográfico, criando ambientes artificiais, como as cidades, ou seja, distanciando-se aí, o homem dos elementos da natureza.

Existem vários fatores que, agregados, corroboram com a poluição do ar, entre eles: o tipo de combustível utilizado no veículo, o tipo de motor, da sua regulagem e do estado de manutenção do veículo. Entretanto, Brasil (2006, p.6-7), faz uma observação, no sentido de chamar a atenção para a quantidade de veículos trafegando pelos centros urbanos sem o devido controle veicular, pois "Individualmente as emissões de um veículo são pequenas. Mas, a concentração de milhares de veículos, fato que ocorre nas grandes cidades, gera toneladas de poluentes por dia”.

Conhecida como a camada de gases que envolvem e protege a Terra, a atmosfera é composta pelo conjunto de vários gases, entre os principais tem-se: o nitrogênio $\left(\mathrm{N}_{2}\right)$, oxigênio $\left(\mathrm{O}_{2}\right)$, argônio (Ar), gás carbônico $\left(\mathrm{CO}_{2}\right)$. Em porcentagens menores, tem-se o neônio, hélio, criptônio, xenônio, hidrogênio, metano, dióxido de nitrogênio $\left(\mathrm{NO}_{2}\right)$, e entre estes, o ozônio $\left(\mathrm{O}_{3}\right)$, responsável por impedir que os raios ultravioletas incidam diretamente sobre a superfície e que venham a provocar efeitos danosos ao meio ambiente (BRAGA et al., 2005).

A constituição da atmosfera, segundo Braga et al. (2005, p.168) é o resultado de: “processos físico-químicos e biológicos iniciados há milhares de anos”. No entanto, a evolução do ser humano, e com ele, aos das suas técnicas, permitiram ao homem modificar e transformar mais rapidamente o meio ambiente, interferindo nos processos ocorridos entre a superfície terrestre e a atmosfera, pela diversificação de suas atividades, culminando com a criação de ambientes artificiais, como os das cidades.

As diversas atividades humanas sejam elas relacionadas à economia, com a diversificação das indústrias pertencentes a vários setores econômicos, assim como as atividades relacionadas ao lazer e ao cotidiano, são responsáveis pela utilização de fontes de energia provenientes da queima de combustíveis fósseis, amplamente utilizados nas indústrias, usinas, nos veículos, como nos aquecedores a gás.

No entanto, a intensa utilização dos combustíveis fósseis tem causado a liberação de substâncias químicas, que tendem a se concentrarem na atmosfera provocando certos desequilíbrios, que tem contribuído para variações na sua composição. Essa alteração atmosférica, potencializada pelas ações humanas, são provindas de diversas fontes classificadas por Braga et al.(2005), como fontes: “móveis e estacionárias”. Ou seja, as indústrias, com suas chaminés, emitem poluentes de forma pontual, pois são objetos fixos, portanto, classificadas como fontes estacionárias. Já os veículos são fontes móveis, devido a sua mobilidade, sendo objetos móveis que circulam por entre vários ambientes. Então esse tipo de fonte poluidora, por outro lado, são fontes móveis e que produzem cargas difusas, se espalhando mais rapidamente pelos espaços, de acordo com o tipo de poluente, a exemplo dos gases expelidos pelos escapamentos dos automóveis que se dispersam em maior velocidade pelo ar. 
Braga et al. (2005), faz uma observação relevante, com relação ao controle da poluição, mostrando que a distinção entre fontes estacionárias e móveis, é fundamental, pois o enfoque para o tratamento do problema é diferente em cada caso. Tal observação recai sobre a análise espacial do fenômeno, uma vez que a poluição gerada por essas duas fontes, estacionárias e móveis, apresenta um raio de propagação distinta, sendo necessária, neste caso, a escolha na escala para a análise do fenômeno. Assim, as áreas atingidas pela poluição do ar podem ter repercussões ambientais, tanto em âmbito local quanto global, pois os fenômenos locais "dizem respeito a problemas de poluição em uma região relativamente pequena, como uma cidade. Os globais envolvem toda a ecosfera, exigindo, portanto, o esforço mundial para enfrentá-lo e controlá-lo” (BRAGA et al. 2005, p.172).

Relatos sobre doenças causadas pela poluição do ar ao homem já foram objeto de investigação de diversos pesquisadores, entre eles o patologista Saldiva, citado por Jesus (1996), descreveu alguns dos sintomas causados pela poluição do ar, manifestado através do fenômeno das chuvas ácidas. Para Saldiva (apud JESUS, 1996, p.146), no caso das chuvas ácidas, esta "têm efeito cumulativo sobre o organismo, podendo acelerar o desenvolvimento de doenças para aquelas pessoas menos saudáveis”.

Os efeitos desse fenômeno, que é uma das fases da poluição do ar, quando inaladas pelo sistema respiratório, tende a se acumular no nariz ou na garganta, do ser humano podendo agravar-se e levar a um quadro clínico na forma de uma asma, rinite e sinusite alérgica. Ou quando "as partículas de ácido sulfúrico e ácido nítrico, solúveis na chuva se infiltram nos brônquios, reduzem os seus mecanismos de defesa contra as infecções oportunistas”, podendo gerar doenças mais graves, como broncopneumonias e doenças nos olhos, como conjuntivite. Enfermidades que podem aparecer ou intensificar no homem, causadas pela alta taxa de concentração de dióxido de enxofre no ar. (SALDIVA, 2002, apud JESUS, 1996, p.146).

As descobertas feitas pelos cientistas, sobre os efeitos negativos que a poluição do ar causa à saúde do ser humano, trouxeram elementos novos para o estudo sobre o fenômeno da poluição do ar, como por exemplo, o fato de que pessoas expostas constantemente ao ar poluído podem vir a desenvolver determinadas doenças respiratórias, implicando em um quadro de sintomas que afeta vários órgãos, como o nariz e a garganta, potencializando o aparecimento e o aumento de casos de asma e sinusite, quando a poluição atinge os olhos, ocorre um maior probabilidade de conjuntivite, nos Brônquios, a poluição se manifesta com a predisposição à broncopneumonia, nos Pulmões ocorre os riscos de enfisema e no coração, a poluição pode causar o aumento nas doenças cardiovasculares (VASCONCELOS et al.,2007).

É indiscutível que o crescente processo de urbanização das cidades tem demonstrado sérias repercussões sobre a qualidade de vida dos habitantes das áreas urbanas, criando problemas ambientais típicos. Um ambiente em constante movimento, à custa da destruição do ambiente natural para a criação de outro ambiente, este sendo (re) criado pelo homem, através de constantes intervenções na natureza. Esse ambiente constitui-se o campo de estudo da Geografia, que pode ser sintetizado por abranger a interação do homem e a natureza. Sendo assim, a Ciência geográfica tem como ponto de partida, estudar as ações do homem sobre o espaço, a partir do momento em que ele transforma a natureza, através do seu trabalho e obedecendo a interesses que variam ao longo do tempo, resultando dessa transformação, o espaço geográfico. 
A partir de então, a intensa produção do espaço geográfico, potencializado pela ação do homem, tem gerado um quadro problemático, pois muitos impactos ambientais estão correndo em conseqüência de uma intensa produção espacial atrelado aos interesses mercadológicos, e estes, em detrimento do meio ambiente. Esses impactos ambientais abrangem não somente o meio ambiente, como também os seres humanos, que se tornam vulneráveis e passíveis diante das ações predatórias decorrentes do atual estágio de desenvolvimento econômico sustentado pelo crescente consumismo de uma sociedade global.

O tema da poluição do ar pode ser encarado como o resultado desse intenso processo de globalização, que ao inserir objetos espaciais para uma maior fluidez do capital, proporciona efeitos negativos ao homem, pois a construção de estradas e rodovias, para a circulação de pessoas e mercadorias, tende a aumentar a frota de veículos circulando por esses espaços, assim como a criação de indústrias para sustentar a crescente demanda de uma sociedade consumista, concorrem para a poluição do ar nas áreas urbanas. Um problema ambiental preocupante, pois segundo Vianello e Alves (1991, p.36), "Estima-se que para cada quilometro quadrado da maioria das grandes cidades, são precipitadas em torno de 20 a 60 toneladas de poeira e fuligem, anualmente”.

Em meio às atribuições inerentes a Ciência Geográfica, o cenário atual envolve desafios para a humanidade e para os cientistas, em buscar soluções que permitam um equilíbrio entre desenvolvimento econômico e meio ambiente, no sentido de que os efeitos negativos movidos pelas atividades econômicas não venham a prejudicar o futuro do planeta e dos seres vivos.

\section{RESULTADOS E DISCUSSÕES}

A produção do espaço urbano na cidade de Natal/RN também traz as mesmas contradições evidenciadas nas grandes cidades, onde o crescimento econômico tem potencializado o aparecimento de problemas ambientais relacionados com o aumento da frota de veículos, observados por autores como Vianello e Alves (1991), Saldiva (2002), Braga et al.(2005). Somente nos últimos anos, que o assunto da poluição do ar, começou a ser discutido, mesmo que de forma tímida, por alguns pesquisadores e, expostas por alguns veículos de comunicação, através de matérias jornalísticas a respeito da poluição do ar.

A área em estudo se caracteriza pela sua intensa atividade comercial e por apresentar um intenso fluxo de veículos e de pessoas, principalmente nos bairros da Cidade Alta e do Alecrim. O Bairro da Ribeira não se constitui enquanto área de intensa atividade comercial, mas possui um fluxo significativo de veículos, notadamente, os transportes coletivos.

\section{Resultados}

Com relação à característica da população amostral, observa-se que a maioria é constituída pelo sexo masculino com $56,48 \%$ e os entrevistados do sexo feminino perfazem os $43,52 \%$. A amostra foi dividida em cinco faixas etárias, entre elas tem-se: a de 10 a 24 anos de idade, com 22,22\%, na faixa entre 25 a 34 anos, com 25\%, no intervalo compreendido entre 35 a 44 anos obteve-se uma percentagem de $25 \%$, na faixa etária entre 45 a 59 anos, com $21.30 \%$ e com faixa etária igual ou superior a 60 anos a percentagem foi de $6,48 \%$. 
Os dados referentes ao local de moradia foram agrupados entre as regiões administrativas da cidade. Assim, diante da variedade dos bairros indicados pelos entrevistados, para melhor efeito de demonstração, a distribuição dos dados foi: Região Leste (37,04\%), Norte (33,33\%), Oeste $(14,82 \%)$, Sul (8,33\%), e outros municípios $(6,48 \%)$, ou seja, uma pequena porcentagem dos entrevistados, responderam que residiam em municípios, alguns inseridos na Região Metropolitana de Natal, como São Gonçalo do Amarante, Parnamirim e Extremoz.

Com relação aos dados sobre o local de trabalho dos entrevistados, a maioria dos da população pesquisada trabalham no bairro da Cidade Alta, com percentagem de 48,16\%, em seguida do Alecrim, com 41,66\% e por fim, o bairro da Ribeira, com 10,18\% dos entrevistados. A interpretação desses dados revela que os maiores fluxos de pessoas que trabalham se concentram nos dois principais bairros comerciais da cidade.

\section{Tempo de Permanência no Trabalho}

Uma informação bastante pertinente, pois revela o tempo que os trabalhadores ficam expostos as emissões dos veículos, referem-se ao quesito que interroga sobre as horas que os entrevistados permanecem em seu ambiente de trabalho diariamente. A maioria da população pesquisada relata permanecer em seu local de trabalho por volta de oito a dez horas diárias, com $81,48 \%$, seguido do tempo compreendido entre uma a sete horas, com $15,74 \%$, e mais de trezes horas diárias, com porcentagem de 1,86\%. Somente uma pequena parcela, de $0,92 \%$, relatou não saber a média de horas que trabalham por dia, devido ao fato da mesma variar no decorrer da semana.

No entanto, a maioria das pessoas, inseridas no universo da amostra, trabalham num período de tempo considerado, de oito a doze horas por dia, conseqüentemente, são pessoas predispostas a sofrerem com os efeitos da poluição do ar, e possivelmente, prédispostas a apresentarem algum tipo de sintoma ou doença de ordem respiratória.

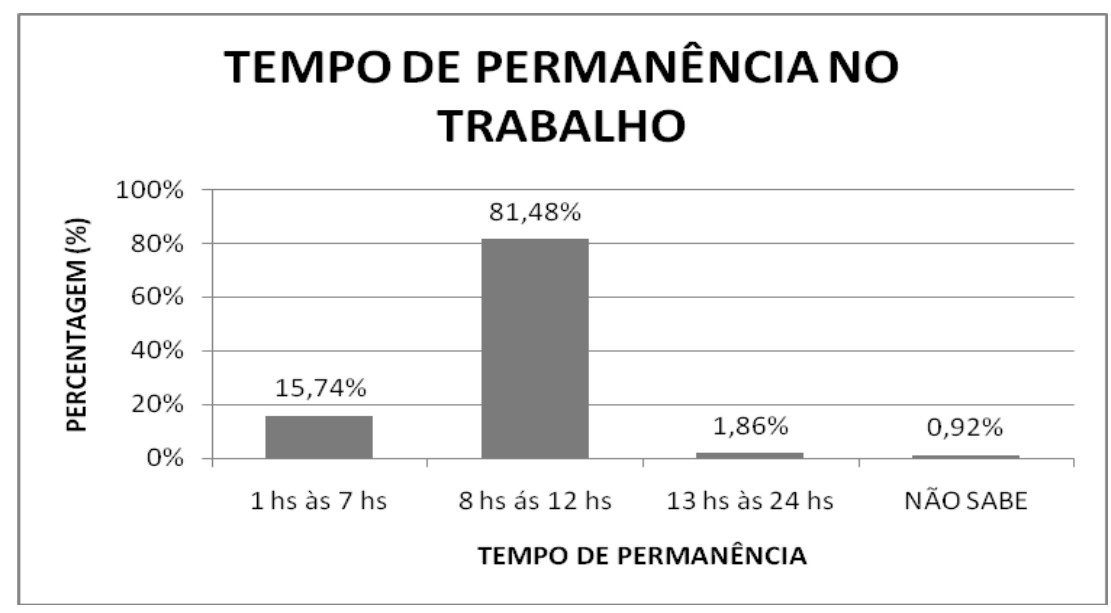

Figura 2 - Tempo de permanência dos entrevistados, segundo locais de trabalho 


\section{Intervalo de Tempo da Última Doença Respiratória}

Para fazer uma correlação com o resultado do tempo de permanência dos trabalhadores em seus locais de trabalho, os entrevistados também responderam o quesito sobre o histórico de doenças respiratórias que porventura, os mesmos tenham adquirido no prazo de tempo recente (dias ou até uma semana) como há mais tempo (semanas ou meses). Os resultados obtidos foram: entre 0 a 1 semana, com 26,86\%, de 2 a 4 semanas, com 25,92\%, mais de 4 meses, com $12,96 \%$ e de 5 a 4 meses, com porcentagem de 10,18\%. Uma parcela considerada dos entrevistados, com 24,08, responderam não saber com precisão, o tempo certo quando ficaram doentes pela última vez, considerando-se assim, como pessoas que nunca ficam doentes, conforme dados visualizados na Figura 3:

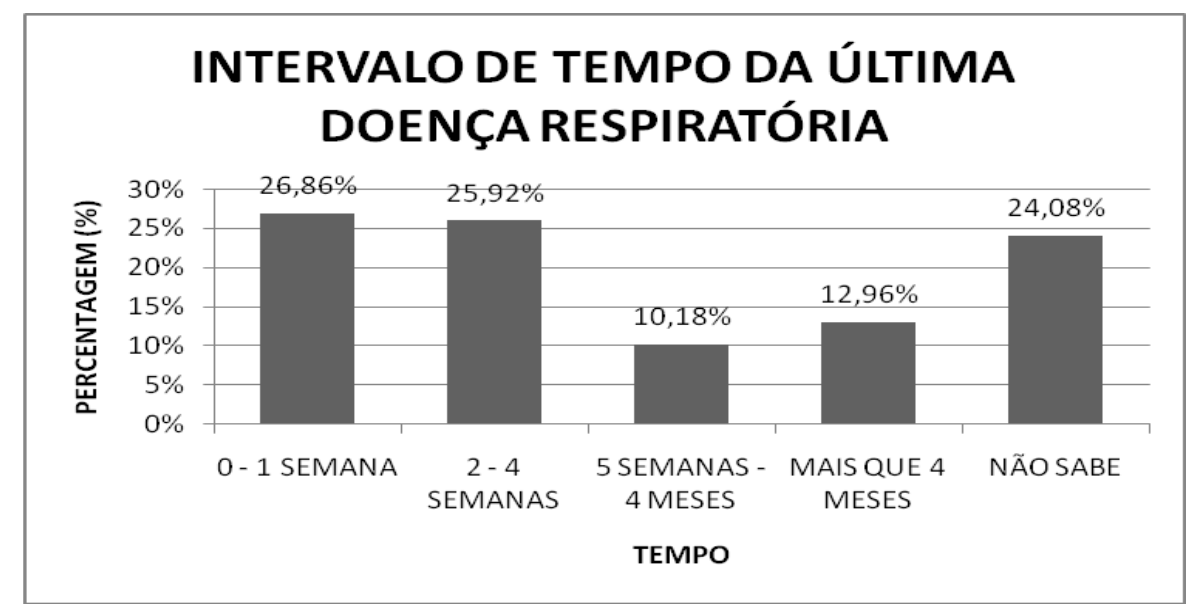

Figura 3 - Intervalo de tempo da última doença respiratória, segundo entrevistados.

\section{Tipo de Problema Respiratório}

No intuito de saber quais os tipos de doenças respiratórias que a população pesquisada costuma adquirir, os resultados convergiram para o seguinte quadro: a maioria dos entrevistados respondeu que costuma apresentar doenças ligadas a gripe/resfriado, com $61,11 \%$, e com alergia/asma, os resultados foram de $28,08 \%$. Os resultados são expostos na Figura a seguir:

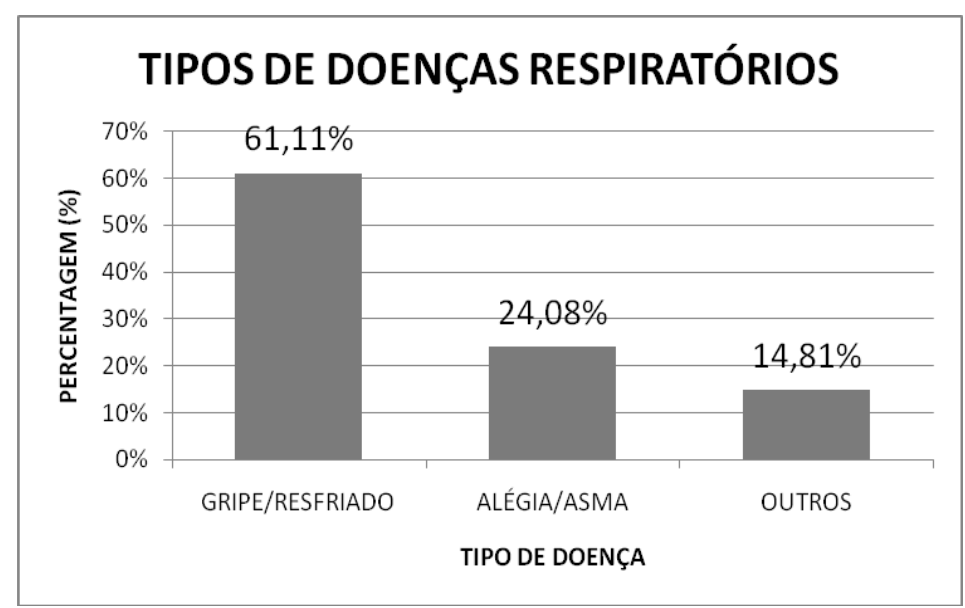

Figura 4 - Tipos de doenças respiratórias, conforme entrevistados 


\section{Freqüência na Aparição dos Problemas Respiratórios}

Objetivando um maior detalhadamente das informações sobre as doenças respiratórias, com relação à freqüência as doenças (gripe/resfriado, alergia/asma), a freqüência das mesmas foram estipuladas seguindo intervalos, entre os mais citados, temse: até um mês, com 26,85\%, mais de 8 meses, com 23,15\%, de 5 a 8 meses, com 17,60\%, de 3 a 4 meses, com $15,74 \%$ e de 1 a 2 meses, com porcentagem de 9,26\%. Conforme Figura 5:

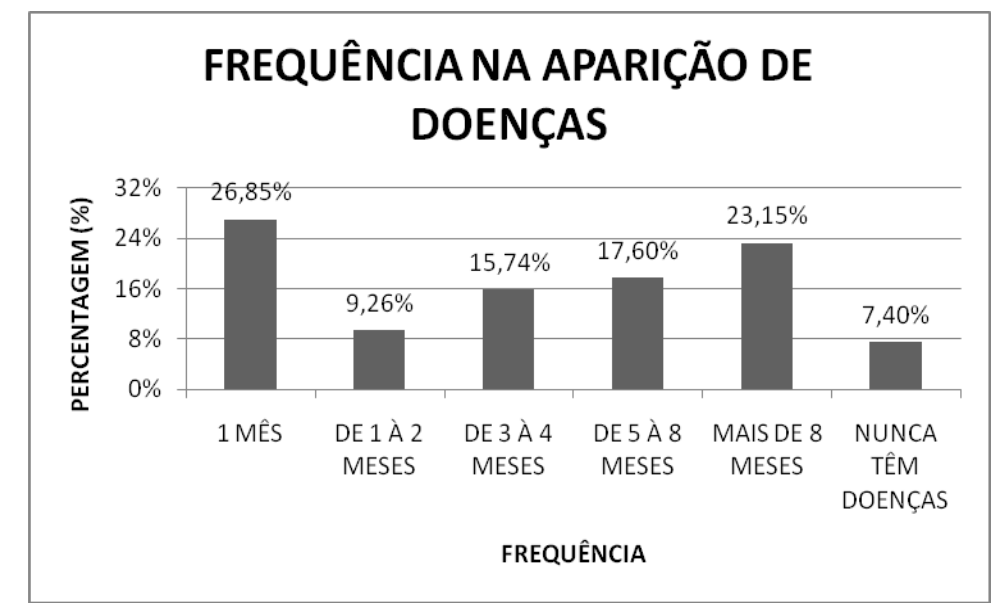

Figura 5 - Freqüência na aparição de doenças respiratórias, entre os entrevistados.

A maior porcentagem entre os entrevistados recaem no quesito que abrange o período de até um mês. Esse dado mostra que a maioria das pessoas entrevistadas tende a adquirem constantemente problemas respiratórios, entre eles, a gripe/resfriado e asma/alergia. Um dado de significativa relevância, pois mostra que essas doenças podem estar diretamente relacionadas com a poluição do ar.

\section{Sintomas da Poluição do Ar}

Uma pergunta final presente nos questionários e que traz uma informação muito importante, pois revela os efeitos da poluição do ar nas pessoas de forma mais expressiva, uma vez que os entrevistados disseram sentir alguns sintomas decorrentes da permanência elevada e da exposição diária em seus locais de trabalho, principalmente, ao final do dia. Os sintomas mais citados pelas pessoas foram: a fuligem no corpo e na roupa, com 50,66\%, irritação nos olhos com, 24,34\%, irritação na garganta e nariz, com 5,40\% dos entrevistados. A Figura 6, a seguir mostra a disposição dos dados: 


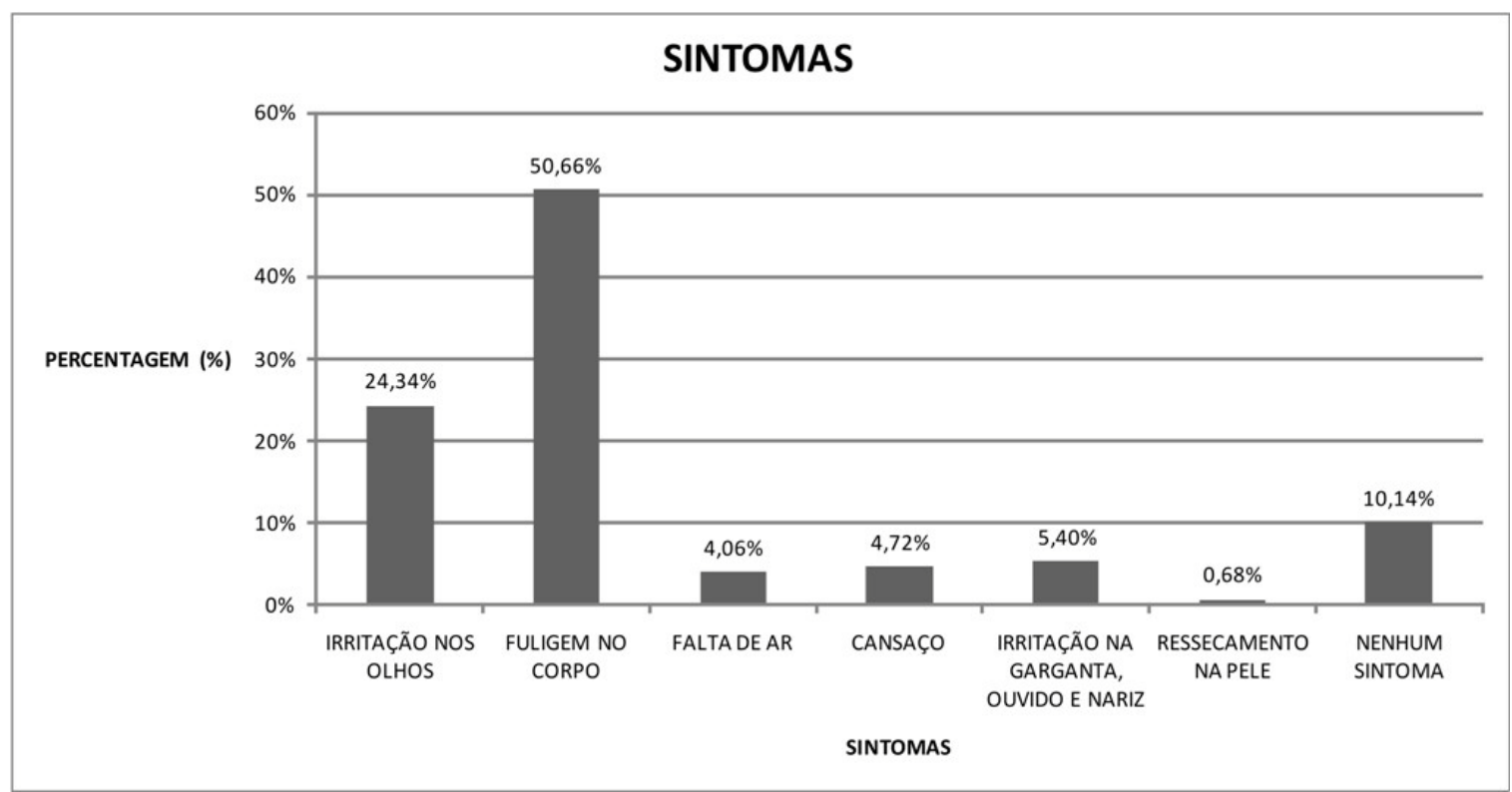

Figura 6 - Principais sintomas da poluição do ar, na opinião dos entrevistados

Durante a investigação dos sintomas da poluição do ar, algumas das pessoas entrevistadas fizeram comentários pertinentes, pois revelam o grau de poluição que essas pessoas estão diariamente expostas. Um desses comentários, feito por um entrevistado que trabalha na Cidade Alta, volta-se para a poluição particulada no ar, representada pela emissão da fuligem pelos carros que circulam por essa área da cidade. Tal poluição tem provocado um desconforto para os trabalhadores do local, pois constantemente essas pessoas se deparam com o corpo e roupas impregnadas de poeira e fuligem. Já os entrevistados, que residem em prédios localizados no bairro, também reclamaram da fuligem dos carros, na forma de sujeira, acumulada nas janelas, portas e nos piso das suas casas.

No bairro do Alecrim, numa das avenidas com maior fluxo de veículos, várias pessoas comentaram que ficam constantemente resfriadas e com irritação nos olhos durante o período em que se encontrava em seus locais de trabalho. Quando perguntado, se os mesmos procuravam atendimento médico quando apresentavam esses sintomas, os entrevistados relataram que não procuravam atendimento médico, pois a irritação nos olhos passava a partir do momento em que os mesmos chegavam a suas residências.

Entretanto, esse questionamento reforça o grau de poluição a qual essas pessoas estão expostas em seu ambiente de trabalho, podendo no futuro, esses efeitos da poluição do ar vir a potencializar efeitos negativos a sua saúde dessas pessoas.

Os resultados obtidos revelam que a poluição do ar nesses centros comerciais apresenta índices consideráveis, representado pelos sintomas verificados na população entrevistada. Aparentemente um sintoma passageiro, mas devido a essas pessoas estarem expostas a um período de tempo significativo diariamente, estes sintomas podem vir a desencadear outros tipos de doenças de ordem respiratórias mais graves.

Um fato que merece a sua devida atenção, tão é a sua importância, tanto por parte dos pesquisadores em aprofundar mais estudos sobre a temática, como por parte do poder público, para intervir com medidas em busca de soluções para reverter ou minimizar esse quadro de poluição do ar nessas áreas. Medidas que podem ser feitas através de Políticas 
Públicas, objetivando a implantação de programas para redução da poluição do ar, através do monitoramento ou com a vistoria dos mesmos, entre outras medidas a serem discutidas.

Quando o estudo propõe a investigação do comportamento da emissão de $\mathrm{CO}_{2}$, na cidade de Natal/RN, algumas considerações devem ser tecidas, entre elas: caso nenhuma medida seja feita em curto prazo, a tendência que haja uma intensificação da poluição do ar e da aparição de doenças ocasionadas por esse tipo da poluição. Pois na cidade, vários fatores contribuem para o agravamento desse quadro, dentre eles e o mais significativo, refere-se ao aumento gradativo da frota de veículos trafegando pela cidade, conforme dados obtidos pelo Departamento Nacional de Transito do Estado - DETRANRN, com a estatística de Natal, exposta na Figura 7:

Figura 7 - Evolução temporal de veículos em Natal/RN. Fonte: ALVES; ALVES, 2009.

A figura 7 reúne dados referentes ao aumento na frota de veículos na cidade, no período de dez anos, compreendido entre o ano de 1998 a 2008. Neste período, observa-se um aumento considerável, de $60 \%$ em 10 anos, na frota de veículos. Um crescimento significativo, e que, se essa tendência continuar a ocorrer, ou seja, o aumento da principal fonte poluidora do ar nas áreas comerciais da cidade trará novos desafios que o Poder Público terá que enfrentar, para que os efeitos da poluição do ar não se multipliquem pelas demais áreas da cidade e nem que a mesma venha a causar sérios problemas para a saúde da população.

\section{CONSIDERAÇÕES FINAIS}

O estudo mostra seus resultados, como também tece algumas considerações sobre prováveis medidas mitigadoras que o Poder Público possa vir a realizar, uma vez que os sintomas manifestados nas pessoas entrevistadas podem ser considerados de ordem pública, e se não forem tomadas nenhuma medida, a tendência é que esses sintomas venham a desencadear casos graves de doenças, como: o câncer, enfisemas pulmonares e 
doenças cardiovasculares, além de gerar no futuro, gastos públicos como o tratamento dessas doenças respiratórias.

Por conseguinte, existem diversas medidas na literatura cientifica, para a amenização dos efeitos da poluição do ar, e conseqüentemente, evitar que casos de doenças de ordem respiratórias atinjam a população. Entre essas medidas tem-se: a arborização das áreas mais movimentadas na cidade, criação de corredores de ventilação, criação de leis que regulamentem a emissão de poluentes veiculares, educação ambiental, no intuito esclarecer aos condutores sobre a importância na regulação e vistoria periódica em seus veículos, pois além de diminuir a emissão de poluentes responsáveis pela poluição do ar, também diminui o consumo excessivo de combustíveis fósseis.

Sobre a qualidade do ar na cidade de Natal/RN, pode-se verificar que a cidade já apresenta um quadro preocupante, com relação aos fatores que potencializam esse tipo de poluição, notadamente, na sua crescente frota de veículos, fazendo surgir, diariamente, os congestionamentos em algumas áreas na cidade, fatores que tem repercutido na aparição de sintomas negativos na saúde das pessoas que trabalham nos centros comerciais pesquisados.

O estudo não tem a pretensão de encerrar o assunto, mas deixá-lo em aberto para que futuras pesquisas possam se orientar através dos resultados deste trabalho, como também que o mesmo possa ter uma repercussão positiva, ao ser utilizado como fonte de consulta tanto para a comunidade acadêmica como para a sociedade em geral. Além de o estudo servir como instrumento para os órgãos públicos para ser usado como subsídio para Políticas Públicas ligadas ao planejamento urbano.

\section{REFERÊNCIAS}

ALVES, Adriano Eduardo Lívio. Monitoramento da Qualidade das Águas de Chuvas conforme Atuação dos Sistemas Sinóticos na Cidade de Natal/RN. 132 f. Dissertação de Mestrado - Universidade Federal do Rio Grande do Norte, Programa de Pós-Graduação em Geografia, Natal, 2009.

BABETTA, Pedro Alberto. Estatística aplicada às ciências sociais. 5.ed. Florianópolis (SC): UFSC, 2002.

BRAGA, Bendito et al. Introdução à engenharia ambiental: o desafio do desenvolvimento sustentável. 2.ed. São Paulo: Pearson Prentice Hall, 2005.

BRASIL. Ministério do Meio Ambiente. Avaliação do programa de controle da poluição do ar por veículos automotores: PROCONVE: 20 anos respirando um ar melhor. $\quad$ BRASILIA, $2006 . \quad$ Disponível em:http://bases.bireme.br/cgibin/wxislind.exe/iah/online/?IsisScript=iah/iah.xis\&src=googl e\&base=REPIDISCA\&lang=p\&nextAction=lnk\&exprSearch=7900\&indexSearch=ID.

Acesso em: 20/05/2009.

GOUVEIA et al. Poluição do ar e efeitos na saúde nas populações de duas grandes metrópoles Brasileiras. Revista Epidemiologia e Serviços de Saúde, v.12(1), n.1, p. 2940, jan/mar. $2003 . \quad$ Disponível em: 
$<$ http://portal.saude.gov.br/portal/arquivos/pdf/3artigo_poluicao_do_ar_efeitos_na_saude.p df $>$. Acesso em 10/05/2009.

JESUS, Emanuel Fernando Reis, A importância do estudo das chuvas ácidas no contexto da abordagem climatológica. Sitientibus. Revista da Universidade Estadual de Feira de Santana, n.14, p.143-153. 1996. Disponível em: <http://www.uefs.br/sitientibus/pdf/14/a_importancia_do_estudo_das_chuvas_acidas.pdf >. Acesso em 10/05/2009.

MACÊDO, Rafael Freire. Inventário de emissões de dióxido de carbono (co2) geradas por fontes móveis no estado do Rio Grande do Norte - período de janeiro de 2003 a junho de 2004. Revista de divulgação científica e tecnológica do Cefetrn - HOLOS, Natal/RN, v. 2, ano 20, Out. 2004. Disponível em:<http://www.cefetrn.br/ojs/index.php/HOLOS/issue/view/15>. Acesso em 12/12/2008.

MEDEIROS, Tásia Hortêncio de Lima. Evolução geomorfológica, (des) caracterização e formas de uso das lagoas da cidade do Natal-RN. Dissertação (Mestrado Geodinâmica e geofísica) Programa de pós-graduação em geodinâmica e geofísica-PPGG, UFRN, Natal, 2001.

MELO, Luciano Rebello da Cunha. Variação da qualidade da água de chuva no início da precipitação. Dissertação (Mestrado em Engenharia Sanitária) - Universidade Federal do Rio Grande do Norte, 2007.

NUNES, Elias. O Meio Ambiente da Grande Natal. Imagem Gráfica, Natal, 2000.

SALDIVA Paulo Hilário Nascimento. BRAGA, Alfesio; PEREIRA, Luiz Alberto Amador. Poluição Atmosférica e seus Efeitos na Saúde Humana. Palestra proferida na Faculdade de Medicina da USP, UNICAMP, 18 a 20 de fevereiro de 2002. Acesso em 12/03/2009. Disponível em: <http://www.libdigi.unicamp.br/document/?down=1039 >. Acesso em: 10/05/2009.

VASCONCELOS, Laura Cristina da Silva et al. A chuva ácida em sala de aula. In: ANAIS DO XII SIMPÓSIO BRASILEIRO DE GEOGRAFIA FÍSICA APLICADA. Natal/RN, 2007. P.1-16.

VIANELLO, Rubens Leite; ALVES, Adil Rainier. Meteorologia básica e aplicações. Universidade Federal de Viçosa (MG), 1991. 